\title{
Behavioural and psychosocial sequelae of severe closed head injury and regional cerebral blood flow: a SPECT study
}

\author{
W Oder, G Goldenberg, J Spatt, I Podreka, H Binder, L Deecke
}

\begin{abstract}
Thirty six patients ( 31 male, 5 female) who had suffered severe closed head injury were re-examined at an average of 39.3 (SD 12.8, range 7-66) months after the injury. Behavioural symptoms were measured using the Giessen test. The relatives' reports were used for data analysis to ensure that results were valid. The neurophysical impairment subscale of the Glasgow assessment schedule was completed by two neurologists, and the number connection test was completed by each patient. The adjective mood scale was completed by each relative. All patients were investigated by single photon emission computerised tomography (SPECT). Exploratory factor analysis using the principal components method was carried out separately for SPECT results and psychological measures and correlations were sought between the resulting factors. Factor analysis of the data from the Giessen test identified social isolation, disinhibition, and aggressive behaviour as major components of post-traumatic personality changes; it indicates that these behavioural features are independent of the level of neurological and neuropsychological impairment, which loaded on a single independent factor. Relatives' psychic health seemed to be relatively resistant to physical and cognitive disability and was mainly affected by disinhibitive behaviour. The highest correlation was between frontal flow indices and disinhibitive behaviour $(p<0.01)$ : the severity of disinhibition increased with lower frontal flow rates. There was a significant but somewhat weaker correlation $(p<0.05)$ between flow indices of the left cerebral hemisphere and social isolation. Low flow values of the right brain regions were related to aggressive behaviour $(p<0.05)$. Neurological and cognitive impairment correlated negatively with the thalamus; worse neurological and cognitive performance indicated by raised scores on the neurophysical scale and on the number connection test was associated with low thalamic flow values. The results support the importance of lesion location in the production of post traumatic behavioural disorders.
\end{abstract}

Residual disabilities following severe closed head injury (CHI) are a complex combination of mental, affective, behavioural, and neurological symptoms. ${ }^{12}$ Disorders of affect and behaviour are judged to be the most important factors for determining the quality of long term recovery. ${ }^{3-6}$ They are often persistent, impose a major burden on the patient's family, and cause the greatest difficulties for patient's long term psychosocial reintegration. ${ }^{37-9}$

Up to now, there has been little information about cerebral correlates of behavioural disorders after severe CHI. Correlations are based more on preconceived notions than on firm localising evidence. ${ }^{41011}$ To our knowledge, only a few studies have systematically investigated relation between behavioural disorders and location of injury, with rather disappointing results. ${ }^{56}$ Furthermore, there are discrepant opinions concerning the relative contributions of organic brain damage and premorbid or other non-organic factors to behavioural sequelae after severe $\mathrm{CHI} .^{312}{ }^{13}$ The question of how much the personality changes after severe CHI in relation to structural or functional brain damage, or both, is a critical issue.

With respect to the location of lesions in severe $\mathrm{CHI}$, a given patient's pattern of residual deficits may be more focal (resulting from cerebral contusions) or more diffuse (resulting from diffuse axonal injury, hypoxia, and increased intracranial pressure) or may include features of both. ${ }^{14-16}$ The frontal and temporal lobes are most commonly affected by contusions, whereas diffuse axonal injury is located mainly within the brain stem, the corpus callosum, and deep white matter, resulting in multiple interruptions of intracerebral connections with consecutive degeneration of thalamic nuclei. ${ }^{14-17}$ From a clinical point of view, we have to keep in mind that the localisation of a focal lesion may be flawed by the presence of occult lesions of the cerebral white matter and a varying degree of concomitant diffuse brain injury. ${ }^{6}$ However, only some of these pathological alterations are detectable by means of morphological brain imaging methods like CT or MRI. ${ }^{17-19}$ In contrast, functional imaging techniques - for example, measurement of cerebral metabolism or cerebral blood flow (CBF) - may reveal a more complete picture of the distribution and extent of brain dysfunction in severe CHI by showing metabolic hypoactivity in the absence of gross structural damage. Single photon emission computer tomography (SPECT) using ${ }^{99 \mathrm{~m}}$ Tc-hexamethyl-propyleneamineoxime $\quad\left({ }^{99 \mathrm{~m}} \mathrm{Tc}-\mathrm{HMPAO}\right)$ has proved to be a useful tool in determining the distribution of regional CBF.

One purpose of the present study was to delineate a profile of post traumatic behavioural and affective disorders and to compare it 
with the patient's pre-existing personality pattern. A second aim was to seek a relation between the degree and nature of behavioural disorders and the pattern of regional cerebral blood flow as evaluated with SPECT.

\section{Patients and methods}

PATIENTS

The study is based on 36 patients ( 31 men, five women) with severe CHI who were admitted consecutively to the neurology clinic for early rehabilitation (within two months after injury). The initial Glasgow Coma Scale (GCS); ${ }^{20}$ score was determined from the reports of neurological assessment in the emergency room. The mean initial score was 6.6 (SD 2.5, range 3-14, median 6) points. All patients with initial GCS scores between 9 and 14 points on admission had experienced further deterioriation in the course of the injury.

Duration of post-traumatic amnesia (PTA) was defined as the interval from the moment of injury until the return of continuous day to day memory and was determined from interviews with relatives and from medical records. The mean duration of PTA was 94.2 (SD 89.6, median 60) days; the minimum duration was five days. PTA was not longer than one week in three patients, between one week and one month in two patients, between one and two months in 14 patients, and longer than two months in 17 patients.

The mean age at the time of injury was 30.2 (SD 10.5 , range $16-58$, median 26.5 ) years. The mean education level was 10.0 (SD 3.5, range 8-16, median 9.5) years. Patients with a history of alcoholism, drug abuse, head injury, or other neuropsychiatric disorders were excluded from the present study. The comprehensive follow up assessment was conducted at an average of 39.3 (SD 12.8, range 7-66, median 41.5) months after the injury. For broad categorisation of the overall outcome of the head injured patients at follow up the widely adopted Glasgow Outcome Scale $(G O S)^{21}$ was used. According to the GOS, 17 patients were Grade V, 13 were Grade IV, and six were Grade III.

METHODS

Assessment of behavioural and emotional disorders (Giessen test)

As patients with $\mathrm{CHI}$ may underestimate their behavioural problems, and this bias can seriously compromise the accuracy of self report data, ${ }^{22}$ the relatives' reports were preferred for data analysis in this study. The Giessen test $(G T)^{2324}$ was administered to a close relative of each patient. The GT, a standardised German personality inventory, consists of a series of $\mathbf{4 0}$ bipolar judgments devised to provide a comprehensive quantitative assessment of behavioural features with emphasis on psychosocial performance. ${ }^{24}$ Each of the 40 items is presented as the positive or negative variation of a certain personality feature with possible scores from -3 to +3 .

Statistical evaluation of the GT is performed on the basis of six subscales consisting of inter related items which have been found by factor analysis. ${ }^{24}$ Each of the six subscales, which is comprised of six single items, can range in score from 0 to 42 . A representative population sample consisting of 1587 subjects ( 732 men, 855 women, age range $18-60$ years) served for standardisation of the GT, and age and sex related standard score values have been published. ${ }^{24}$ The six bipolar subscales were labelled by Beckmann et al as follows:

(1) Social response: negative (defined as nonrespected, non-accepted, unattractive) versus positive (defined as respected, accepted, attractive).

(2) Conflict behaviour: dominance (defined as rigid, obstinant, aggressive, impatient) versus submissive (conformist, submissive, quiet, patient).

(3) Self control: impulsiveness, "under controlled" versus anancastic behaviour, "over controlled."

(4) Mood: hypomania versus depression.

(5) Extraversion-introversion: extraversion (defined as open minded, close to others, trusting, freely expressing feelings) versus introversion (defined as not open-minded, not close to others, suspicious, retaining feelings). (6) Social competency: social competency (defined as self confident, active, competing behaviour) versus lack of social competency (defined as retiring, inactive, shy in sexual contacts, lack of competition). ${ }^{24}$

The GT has been shown to have significant diagnostic and predictive utility with respect to psychiatric and neurological populations including head injured patients. ${ }^{25-28} \mathrm{~A}$ close relative was asked to complete the GT twice, once for the head injured patient's "current" (post-traumatic) personality and once retrospectively for pre-injury personality.

\section{Neurological examination on follow up}

A detailed neurological examination was carried out for each patient. For semiquantitative evaluation of neurological deficits the subscale "neurophysical impairment" of the Glasgow assessment schedule (GAS) ${ }^{29}$ was used. It comprises a series of eight neurological items which can be scored 0,1 , or 2 corresponding to normal, moderately severe, or severe. The GAS has good inter rater reliability and concurrent validity with the global ratings of GOS. ${ }^{29}$ After the neurological examination the neurological scale was completed independently by two experienced neurologists and the average score was taken.

\section{Number connection test}

The number connection test (NCT), a simple bedside psychometric test, ${ }^{30}$ was completed by each patient. It is a visual-motor sequencing task with two parts. The first, part $\mathrm{A}$, consists of 25 circles consecutively numbered from 1 to 25 of a sheet of paper. The patient is required to connect the circles in numerical sequence as quickly as possible. After completion of part $A$, part $B$, which is considerably more difficult, is administered. In part $B$, circles are marked either by letters or by numbers, and the patient has to alternate between numerical and alpha- 
betical sequences $(1-\mathrm{A}-2-\mathrm{B} . .$.$) . The score is the$ time for completion of part $B$ expressed in seconds. $^{31}$

\section{Assessment of the relatives burden}

For evaluation of the amount of strain or distress experienced by the close relative, the adjective mood scale (AMS) ${ }^{323}$ was completed by each relative. The AMS is a brief self report consisting of 28 bipolar adjectives related to mood (scoring ranges from 0 to 56). The AMS can be easily administered and has been extensively evaluated for its reliability and validity. $^{32}$

\section{SPECT}

A dual head rotating scintillation camera (Siemens Dual Rota ZLC37) connected to a dedicated computer system (Nodecrest Micas 2000) was used for SPECT. The camera heads were equipped with high resolution, low energy, all purpose collimators, yielding a spatial resolution of $12 \mathrm{~mm}$ full width at half maximum in the axial plane. The patients were placed on a reclining dentist's chair. A dose of approximately $20 \mathrm{mCi}{ }^{99 m} \mathrm{Tc}-\mathrm{HMPAO}$ was administered intravenously. The lipophilic agent crosses the blood-brain barrier and is deposited in the brain cells within 3-4 min after injection. Uptake of HMPAO is closely (about 95\%) correlated with cerebral blood flow. $^{34}$ Data acquisition started 10 minutes after injection of the tracer. Rotation time was 30 minutes for 60 projections $(2 \times 30$ angles; $100 \mathrm{~s} /$ angle) with a sampling distance of $3 \cdot 125 \mathrm{~mm}$. Projections were filtered with a filter of variable shape and size $\mathrm{s}^{35}$ to reduce poisson noise, ${ }^{36}$ and data were reorganised in a sinogram. After correction of attenuation, ${ }^{37}$ $3.125 \mathrm{~mm}$ thick cross sections were reconstructed by filtered back projection in $128 \times 128$ matrices using a soft Shepp-Logan filter. Seven cross sections were consecutively summed to give a set of $21.9 \mathrm{~mm}$ thick transverse slices. $^{3839}$ For semiquantitative evaluation of HM-PAO uptake, four consecutive slices of $21.9 \mathrm{~mm}$ thickness were displayed and regions of interest were drawn by hand according to anatomical templates. Regions were drawn in the hemisphere that showed fewer lesions and were then mirrored to the other hemisphere. Indices of regional isotope uptake were calculated by dividing the count rate of a region by the mean count of all regions taken together. Evaluation of SPECT studies was performed without knowledge of the patient's identity or behavioural symptoms.

\section{STATISTICAL ANALYSIS}

For data management and statistical calculations SPSS software ${ }^{40}$ was used. Descriptive statistics were performed first. To compare differences in behavioural and psychosocial performance as assessed by means of the GT, analysis of variance (patients' score before and after injury versus scores of representative population) paired t-test (scores before and after injury) were computed. A correlational matrix of all variables was constructed using the Pearson product-moment coefficient. To examine the underlying structure of the data, exploratory factor analysis, which classifies groups of variables, was carried out separately on psychological measures and SPECT results, using the principal components method. Factors were interpreted if eigenvalues were greater than 1.0 and if the factor contained variables with rotated factor loadings of 0.4 or more. The Pearson productmoment correlation coefficient analysis was performed on the results of both factor analyses. The results of the tests are to be interpreted in a descriptive sense.

\section{Results}

PERSONALITY PROFILE

Analysis of variance disclosed that the average pre-traumatic personality profile of the head injured patients, as assessed by the retrospective ratings of the relatives, was of a more rigid type (GT subscale 2) than that of a normal male population of comparable age (327 men, aged 18-34; ANOVA, $F=7 \cdot 61$, $\mathrm{df}=362, \mathrm{p}<0.01)$. In addition, there was a trend towards less controlled behaviour (GT subscale 3 ) but it did not reach statistical significance $(F=3.09, \mathrm{df}=362, \mathrm{p}=0.079)$. The average pre-traumatic scores on the remaining subscales did not differ from the scores of the control group.

There were highly significant differences between mean post traumatic scores of the patients and the scores of controls on five of the six subscales of the GT. Only on subscale 3 (control behaviour) the difference failed to reach statistical significance (ANOVA, $F=2 \cdot 75, \mathrm{df}=362, \mathrm{p}=0 \cdot 098$ ).

Severe CHI caused highly significant changes on the social response scale and social competency scale: patients were rated less socially attractive $(t=4 \cdot 23, \quad \mathrm{df}=38$, $\mathrm{p}<0.001)$ and less socially competent $(t=4.24, \mathrm{df}=38, \mathrm{p}<0.001)$ than before the trauma. There was a trend towards increased introversion and social withdrawal as indicated by raised scores on subscale 5 (extraversionintroversion; $t=2 \cdot 29, \mathrm{df}=38, \mathrm{p}<0.05$ ). Subscale 2 (conflict behaviour) showed only slight changes towards greater rigidity, and subscale 4 (mood) towards more depressed mood. The average post traumatic score of subscale 3 of the GT (self control) was identical to the pretraumatic score (fig 1).

RESULTS OF FACTOR ANALYSIS

Clinical variables-A principal components analysis (PCA, with Varimax rotation) was performed on the post traumatic scores of the six subscales of the GT and the results of the neurological examination and the NCT scores of the head injury victims, as well as the AMS scores of the relatives. With the exception of neurological deficits ("neurophysical impairment" of the GAS), which were skewed towards minor residual deficits, all variables had a fairly normal distribution. PCA produced four factors with an eigenvalue greater than 1. The factor loadings of the rotated 


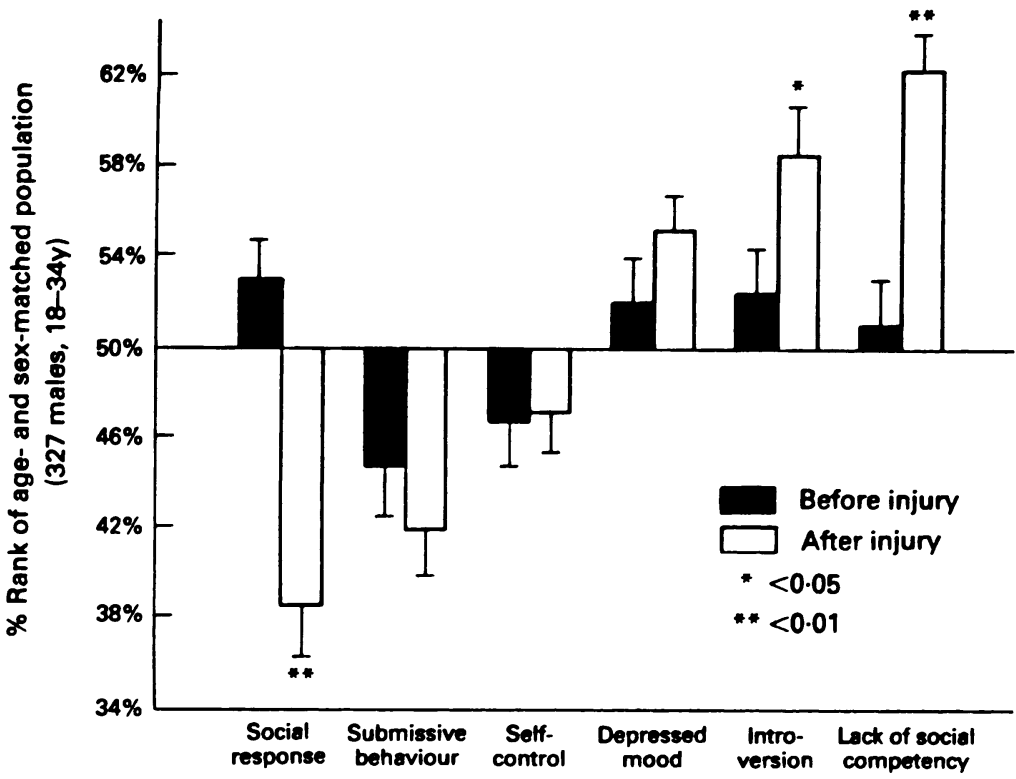

Figure Differences between the pre-traumatic and post-traumatic personality profile (paired $t$ test).

solution are shown in table 1. Introversion, lack of social competence, and lack of social attractiveness loaded highly on the first factor. This factor was labelled "social isolation." The second factor, which was called "neurological and cognitive impairment," had high loadings in the neurological scores and NCT scores. The third factor was influenced mainly by low scores on the depression and self control subscales of the GT. It was referred to as the "disinhibitive" factor. The loading of a third trait, the relatives' high scores of the AMS on this factor, suggests that disinhibitive behav-

Table 1 Loadings of the four factors on the psychological measures and clinical variables derived by means of PCA (Varimax rotation)

\begin{tabular}{lcccc}
\hline & Social isolation & $\begin{array}{l}\text { Neurological or } \\
\text { cognitive impairment }\end{array}$ & $\begin{array}{l}\text { Disinhibitive } \\
\text { behaviour }\end{array}$ & $\begin{array}{c}\text { Aggressive } \\
\text { behaviour }\end{array}$ \\
\hline Introversion & 0.88 & -0.12 & 0.00 & -0.07 \\
Social weakness & 0.81 & 0.02 & -0.04 & 0.35 \\
Social response & -0.81 & -0.29 & 0.11 & 0.37 \\
NCT & 0.23 & 0.90 & -0.12 & 0.16 \\
Neurological deficits & -0.19 & 0.85 & 0.26 & -0.19 \\
Hypomania & 0.29 & -0.11 & 0.78 & -0.17 \\
Distress of relatives & 0.08 & -0.12 & 0.65 & -0.30 \\
Self control & -0.14 & 0.05 & -0.43 & -0.02 \\
Conflict behaviour & 0.00 & -0.01 & 0.03 & 0.90 \\
\hline
\end{tabular}

Table 2 Loadings of the four factors on the SPECT results derived by means of PCA (Varimax rotation)

\begin{tabular}{llccr}
\hline & Thalamus & Left hemisphere & Right hemisphere & \multicolumn{1}{c}{$\begin{array}{l}\text { Frontal } \\
\text { lobes }\end{array}$} \\
\hline Left thalamus & 0.83 & 0.50 & 0.05 & -0.04 \\
Right thalamus & 0.95 & -0.08 & 0.13 & 0.12 \\
Left temporal lobe & 0.11 & 0.92 & 0.17 & 0.21 \\
Right temporal lobe & 0.10 & 0.22 & 0.93 & -0.04 \\
Left frontal lobe & 0.02 & 0.37 & -0.11 & 0.87 \\
Right frontal lobe & 0.15 & -0.19 & 0.60 & 0.68 \\
\hline
\end{tabular}

Table 3 Correlations between psychological measures and SPECT results (Pearson productmoment correlation coefficients)

\begin{tabular}{lllcc}
\hline & Social isolation & $\begin{array}{l}\text { Neurological or } \\
\text { cognitive impairment }\end{array}$ & $\begin{array}{l}\text { Disinhibitive } \\
\text { behaviour }\end{array}$ & $\begin{array}{c}\text { Aggressive } \\
\text { behaviour }\end{array}$ \\
\hline Thalamus & -0.21 & $-0.37^{\star}$ & 0.04 & -0.13 \\
Left hemisphere & $0.38^{\star}$ & -0.06 & -0.28 & -0.03 \\
Right hemisphere & -0.29 & 0.06 & -0.12 & $0.37^{\star}$ \\
Frontal lobes & 0.00 & -0.26 & $0.62^{\star \star}$ & 0.01 \\
\hline
\end{tabular}

${ }^{\star} \mathrm{p}<0.5,{ }^{\star \star} \mathrm{p}<0.01$. iour causes the highest amount of distress for relatives of head injury victims. On the fourth factor, conflict behaviour loaded highly. This factor was labelled "agressiveness."

Regional cerebral blood flow-With respect to SPECT data, two steps were taken to enhance the power of correlations and to reduce data for making them amenable to interpretation. Firstly, consistent with neuropathological evidence of the maximum pathology in severe $\mathrm{CHI},{ }^{101416}$ anatomical regions in the factor analysis were restricted to frontal and temporal lobes and the thalamus. Secondly, we performed a principal components analysis (with Varimax rotation) of the regional cerebral blood flow values mentioned above. As table 2 shows, principal components analysis yielded four factors: one loading high on both thalami ("thalamus"), one higher on left than on right brain regions ("left hemisphere"), one higher on right than on left regions ("right hemisphere"), and one factor loading high on both frontal lobes.

CORRELATIONS BETWEEN CLINICAL VARIABLES AND REGIONAL CEREBRAL BLOOD FLOW

A Pearson product-moment correlation coefficient analysis was carried out on the results of both factor analyses (clinical variables $v$ regional cerebral blood flow). Table 3 shows the resulting correlation coefficients. The highest positive correlation was obtained between frontal flow indices and disinhibitive behaviour ( $p<0.01$ ). Disinhibitive behaviour (as indicated by low scores on the GT subscales 3 and 4) correlated with low regional cerebral blood flow in frontal lobes. In addition, there was a significant but weaker correlation $(p<0.05)$ between flow indices of the left cerebral hemisphere and the social isolation factor-that is, higher left cerebral hemispheric flow values were associated with worse social role functioning. Thirdly low flow values of right brain regions were associated with aggressive behaviour (low scores on GT subscale 2, p < 0.05). Neurological and cognitive impairment correlated negatively with the thalamus factor-that is, worse neurological and cognitive performance as indicated by raised scores on the neurophysical scale and on NCT was associated with low thalamic flow values.

\section{Discussion}

PERSONALITY PROFILES

The importance of premorbid psychosocial and personality characteristics in the genesis of post-traumatic behavioural dysfunction has repeatedly been pointed out ${ }^{8112}$ and the pretraumatic GT profiles of our patients confirm that $\mathrm{CHI}$ patients do not represent a typical cross section of the population but are often maladjusted in some way, risk takers, and impulsive in behaviour. ${ }^{4142}$

With respect to the main patterns of personality change caused by severe $\mathrm{CHI}$, our results accord with previous findings. Patients had fewer social contacts than before the injury. ${ }^{43-45}$ Withdrawal from social interaction 
is a major characteristic of survivors of severe CHI. ${ }^{8946}$ In previous reports, the trend towards social isolation was noted even in young adults who had been socially active before the injury ${ }^{96}$ and who were considered "good recovered". 45 Oddy et al pointed out that the reason for the loss of social contact was not to be found in physical restrictions but in personality changes such as restlessness, irritability, and impatience. ${ }^{4347}$ Head injured patients often disregard conventional social norms, and have difficulties in controlling and suppressing aggression and impulsive reactions. ${ }^{34648}$ Aspontaneity and affective changes of the depressive type are extremely common after brain injury and contribute to withdrawal from social roles. ${ }^{3713}$

FACTOR ANALYSIS OF CLINICAL VARIABLES

The factor analysis of the GT data disclosed social isolation, disinhibition, and aggressive behaviour as the main components of posttraumatic personality changes and shows that these behavioural features are independent of the level of neurological and neuropsychological impairment, which loaded on a single, independent factor. Relatives' mental health seemed to be relatively resistant to patients' physical and cognitive disability and was affected mainly by disinhibitive behaviour. This agrees with previous findings that the relative's stress relates more to lack of temper control and affective changes than to physical impairments. ${ }^{94649}$

CORRELATIONS BETWEEN CLINICAL VARIABLES AND REGIONAL CEREBRAL BLOOD FLOW

It is well known that orbital frontal damage after head injury often leads to the so called disinhibition syndrome with disinhibition, euphoria, and puerilism. ${ }^{10}$ This link is clearly supported by the results of the present correlational study.

With respect to laterality of flow-reduction, the finding that low left cerebral hemispheric flow values were associated with a relatively less pronounced social isolation could be interpreted as meaning that patients with relatively preserved left hemisphere functions may be more aware of their residual deficits and problems in social adjustment. Withdrawal from social interaction may be the easiest coping strategy available. ${ }^{813}$

As regards right hemispheric flow values, our findings contrast with previous notions: aggressive behaviour after head injury was discussed as a feature of a focal temporal lobe injury or a loss of learned inhibitory controls due to frontal lobe injury. ${ }^{50}$ Right hemisphere lesions may also lead to emotional and affective disturbances. Unrealistic self appraisal and denial of disability, which are often found with right hemisphere lesions, may result in social conflicts. ${ }^{13}$ Using PET scan procedures, Starkstein et al found that manic episodes occurring after brain injury of different aetiology were asssociated with damage in the right cerebral hemisphere. ${ }^{51}$ They suggested a major role for the basal region of the right temporal lobe in the regulation of mood.
According to the centripedal model of $\mathrm{CHI},{ }^{52}$ progressively deeper functional and structural disconnections produced by diffusal axonal injury (DAI) result in more extensive diffuse brain damage. There is neuropathological evidence of degeneration of thalamic nuclei in patients with severe DAI. ${ }^{14}{ }^{16}$ The functional dependence on multiple cortical and subcortical connections may make thalamic flow values interpretable as a potential index of the extent of diffuse brain damage in $\mathrm{CHI}$. The negative correlation between the severity of neurological and cognitive impairment and thalamic flow values established in this study may confirm previous findings that the extent of DAI is associated with the overall and neuropsychological outcome. ${ }^{1819}$ Accordingly, an association between thalamic flow and various measures of cognitive function has also been found in a study assessing relations between neuropsychology and SPECT in the same patients. ${ }^{53}$

Whether behavioural disturbances should be considered as organic or non-organic in origin is an important theoretical and practical issue. Abnormal personality patterns might be the direct result of traumatic brain damage. ${ }^{10}$ In previous reports the severity of behavioural disturbances was related to the degree of brain damage. $^{7546}$ but the deficits may not have been due entirely to organic brain damage. ${ }^{411}$ Premorbid psychosocial disorders were judged more important than brain damage in the genesis of post-traumatic psychiatric disorders. ${ }^{12}$ Premorbid personality traits-particularly those of a less pleasant nature-may become exacerbated after injury. ${ }^{450}$ Organic changes may also trigger secondary changes, ${ }^{44}$ perhaps as a result of psychological reaction (that is, personality adjustment problems) to the injury. ${ }^{354}$ Increased awareness of impaired functioning with the passage of time has also been discussed as a possible mediator of emotional and behavioural disorders in patients with chronic head injury. ${ }^{85}$ In this context, our results offer some support for the importance of lesion location in the production of post-traumatic behavioural disorders. However, even the highest correlation found, that between frontal flow values and disinhibition, accounted at best for about $40 \%$ of variance. The proportion of organic and non-organic contributions to the head injured patient's psychosocial performance, and thus their respective contributions to the severity of behavioural disorders, requires further prospective studies.

Some limitations of the present study have to be considered. The patients studied may not be a representative sample of patients suffering severe head injury. They were selected by admission policy, which is likely to bias the sample with respect to the base population of severely head injured patients. In comparison to other series of consecutive admissions, ${ }^{485654}$ our patients had in general suffered more severe head injuries. This bias means that our study can have no epidemiological implications concerning the prevalence of problems in a representative sample of 
survivors of severe CHI. It also means that caution should be exercised in extrapolating the findings to other samples of severely head injured patients.

Interpretation of the GT profiles must proceed cautiously, given the absence of validated scales sensitive to the particular affective and behavioural characteristics of head injured patients in German speaking countries. Because the sample of patients with chronic head injury was rather small in proportion to the number of variables examined, statistical testing is to be regarded as exploratory rather than confirmatory. Nonetheless, the main results seem to be clinically relevant and are in keeping with common empirical evidence of a relation between behavioural disorders and location of brain injury. ${ }^{213}$

1 Jennett B. Scale and scope of the problem. In: Rosenthal $M$, Griffith ER, Bond MR, Miller JD, eds. Rehabilitation of the adult and child with traumatic brain injury. 2nd ed Philadelphia: F A Davis 1990:3-7.

2 Levin HS, Grossmann RG, Rose JE, Teasdale G. Long-term neuropsychological outcome of closed head injury. $\mathscr{f}$ Neurosurg 1979;50:412-22.

3 Brooks N. Personality change after severe head injury. Acta Neurochir (Wien) 1988;44 (suppl):59-64.

4 Brooks N. Behavioural and social consequences of severe head injury. In: Deelman BG, Saan RJ, van Zomeren AH, eds. Traumatic brain injury. Clinical, social and rehabilitational aspects. Amsterdam: Swets and Zeitlinger, 1990:77-88.

5 Levin HS, Grossmann RG. Behavioural sequelae of closed head injury. A quantitative study. Arch Neurol 1978; 35:720-7

6 Levin HS, High WM, Goethe KE, Sisson RA, Overall JE, Rhoades HM, et al. The neurobehavioural rating scale: assessment of the behavioural sequelae of head injury by the clinician. $f$ Neurol Neurosurg Psychiatry 1987 50:183-93.

7 Brooks N, Campsie L, Symington C, Beattie A, McKinlay W. The five year outcome of severe blunt head injury: a relative's view. $\mathcal{f}$ Neurol Neurosurg Psychiatry 1986; re:764-70.

8 Fordyce DJ, Roueche JR, Prigatano GP. Enhanced emotional reactions in chronic head trauma patients. $f$ tional reactions in chronic head
Neurosurg Psychiatry 1983;46:620-4.

9 Thomsen IV. The patient with severe head injury and his family. A follow up study of 50 patients. Scand $\mathcal{f}$ Rehab Med 1974:6:180-3

10 Stuss DT, Benson FD. The frontal lobes. New York: Raven Press, 1986.

11 Rosenthal M, Bond MR. Behavioral and psychiatric sequelae. In: Rosenthal M, Griffith ER, Bond MR, Miller JD, eds. Rehabilitation of the adult and child with traumatic brain injury. 2nd ed. Philadelphia: FA Davis 1990:179-92

12 Bond MR. Assessment of the psychosocial outcome after severe head injury. Acta Neurochir (Wien) 1976;34: 57-70.

13 Prigatano GP. Personality and psychosocial consequences of brain injury. In: Prigatano GP, Fordyce DJ, Zeiner HK Roueche JR, Pepping M, Wood BC, eds. Neuropsycho-
logical rehabilitation after brain injury. Baltimore, London: John Hopkins University Press, 1986:29-50.

14 Adams JH, Graham DI, Murray LS, Scott G. Diffuse axonal injury due to non-missile injury in humans: an analysis of 45 cases. Ann Neurol 1982;12:557-63.

15 Snoek J. The pathophysiology of head injuries. In: Deelman BG, Saan RJ, van Zomeren AH, eds. Traumatic brain injury. Clinical, social, and rehabilitational aspects. Amsterdam: Swets and Zeitlinger 1990:9-22.

16 Strich S. Diffuse degeneration of the cerebral white matter in severe dementia following head injury. $\boldsymbol{f}$ Neurol Neurosurg Psychiatry 1956;19:163-85.

17 Teasdale G, Mendelow D. Pathophysiology and head injuries. In: Brooks N, ed. Closed head injury. Psychological, social, and family consequences. Oxford: Oxford logical, social, and family conse
University Press 1984:4-36.

18 Levin HS, Williams D, Crofford MJ, High WM, Eisenberg HM, Amparo EG, et al. Relationship of depth of brain lesions to consciousness and outcome after closed head injury. I Neurosurg 1988;69:861-6.

19 Wilson JTL, Wiedmann KD, Hadley DM, Condon B, Teasdale G. Early and late magnetic imaging and neuroTeasdale G. Early and late magnetic imaging and neuro-
psychological outcome after head injury. $\mathscr{Y}$ Neurol Neuropsychological outcome after head
surg Psychiatry 1988;51:391-6.

20 Teasdale G, Jennett B. Assessment of coma and impaired consciousness. A practical scale. Lancet 1974;i:81-4.

21 Jennett B, Bond MR. Assessment of outcome after severe brain damage. Lancet $1975 ; \mathrm{i}: 480-4$.

22 McKinlay WW, Brooks ND. Methodological problems in assessing psychosocial recovery following severe head injury. $\mathcal{F}$ Clin Neuropsychol 1984;6:87-9.

23 Beckmann D, Richter HE, eds. Effahrungen mit dem GiessenTest (GT). Bern, Stuttgart, Wien: Hans Huber, 1979.

24 Beckmann D, Brähler D, Richter HE Der Giessen-Test (GT). Ein Test für Individual und Gruppendiagnostik.
Handbuch. 3rd ed. Bern, Stuttgart, Wien: Hans Huber, 1983

25 Hell D. The spouses of depressive and schizophrenic patients. A controll

26 Michael C. Die Untersuchung von Persönlichkeitsfaktoren bei hirngeschädigten Personen mit dem Giessen-Test [Dissertation]. Munich: Universität München, 1987.

27 Poewe W, Gerstenbrand F, Ransmayr G, Ploerer S. Premorbid personality of Parkinson patients. $\mathcal{f}$ Neural Trans 1983;19 (suppl):215-24.

28 Richter J, Eisemann M, Richter G. Perceived parental rearing and state versus trait aspects of adult depression. Psychopathology 1991;24:25-30.

29 Livingstone MG, Livingstone HM. The Glasgow assessment schedule: clinical and research instrument of head ment schedule: clinical and research instrume

30 Conn HO. The trailmaking and number connection tests in the assessment of mental state in portal systemic encephathe assessment of mental state in portal syst
lopathy. Am $₹$ Dig Dis 1977;22:541-50.

31 Conn HO, Lieberthal MM. The hepatic coma syndromes and lactulose. Baltimore: Williams and Wilkins, 1979.

32 Von Zerssen D, Koeller DM. Klinische Beurteilungs-Skalen aus dem Münchner Psychiatrischen Informations-System (PSYCHIS München). Die Befindlichkeits-Skala. Weinheim: Beltz Test, 1976.

33 Von Zerssen D. Clinical self-ratings scales (CSRS) of the Munich psychiatric information system (PSYCHIS München). In: Sartorius N, Ban TA, eds. Assessment of depression. Berlin: Springer, 1986:270-303.

34 Neirinckx RD, Canning LR, Piper IM, Nowotnik DP, Pickett RD, Holmes RA, et al. Technetium-99m d, 1-HM-PAO: a new radiopharmaceutical for SPECT imaging of regional cerebral blood perfusion. $\mathcal{f}$ Nucl Med 1987;28:191-202.

35 Todd Popropek A, Di Paola R. The use of computers for imaging processing in nuclear medicine. IEEE Trans $\mathrm{Nucl}$ Sci 1982;21:1299-309.

36 King MA, Schwinger RB, Doherty PW, Penney BC. Twodimensional filtering of SPECT images using Metz and Wiener filters. $f$ Nucl Med 1984;25:1234-40.

37 Bellini S, Piacentini M, Cafforio C, Rocca F. Compensation of tissue absorption in emission tomography. IEEE Trans Acous Speech Sign Proc ASSP 1979;27:213-8.

38 Podreka I, Suess E, Goldenberg G, Steiner M, Brücke T, Müller C, et al. Initial experience with Tc-99mhexamethylprophyleneamineoxime (Tc-99m-HM-PAO) brain SPECT. $尹$ Nucl Med 1987;28:1657-66.

39 Podreka I, Baumgartner C, Suess E, Müller C, Brücke T, Lang W, et al. Quantification of regional cerebral blood flow with IMP-SPECT, reproducibility, and clinical row with IMP-SPECT, reproducibility, and

40 SPSS Inc. SPSSX user's guide. 2nd ed, New York: McGrawHill, 1986

41 Fahy TJ, Irving MH, Millac P. Severe head injuries. Lancet

42 Weddell $R$, Oddy $M$, Jenkins $D$. Social adjustment after rehabilitation: a two-year follow-up of patients with severe head injury. Psychol Med 1980;10:257-63.

43 Oddy $M$, Humphrey $M$. Social recovery during the year following severe head injury. $\mathcal{F}$ Neurol Neurosurg Psychiatry

44 Oddy M. Head injury and social adjustment. In: Brooks N, ed. Closed head injury. Psychological, social, and family consequences. Oxford: Oxford University Press, 1984: 108-22.

45 Tate RL, Lulham JM, Broe GA. Strettles B, Pfaff A. Psychosocial outcome for the survivors of severe blunt head injury: the results from a consecutive series of 100 patients. $f$ Neurol Neurosurg Psychiatry 1989;52: 1128-34.

46 Thomsen IV. Late outcome of very severe blunt head trauma: a 10-15 year second follow-up. $f$ Neurol Neurosurg Psychiatry 1984;47:260-8.

47 Oddy M, Humphrey M, Uttley D. Subjective impairment and social recovery after closed head injury. 7 Neurol Neurosurg Psychiatry 1978;41:611-6.

48 Brooks DN, McKinlay W. Personality and behavioural change after severe blunt head injury - a relative's view. $f$ Neurol Neurosurg Psychiatry 1983;46:336-44.

49 Oddy M, Humphrey M, Uttley D. Stresses upon the relatives of head injured patients. Br $\mathcal{F}$ Psychiatry 1978; 133:507-13.

50 Wood RL. Behaviour disorders following severe brain injury: their presentation and psychological management. In: Brooks N, ed. Closed head injury. Psychological, social, and family consequences. Oxford: Oxford University Press, and family conse

51 Starkstein SE, Mayberg HS, Berthier ML, Fedoroff P, Price TR, Dannals RF, et al. Mania after brain injury: neurorTR, Dannals RF, et al. Mania after brain injury: neuror-
adiological and metabolic findings. Ann Neurol 1990;27:652-9.

52 Ommaya AK, Gennarelli TA. Cerebral concussions and traumatic unconsciousness. Correlation of experimental
and clinical observations on blunt head injuries. Brain and clinical observ

53 Goldenberg G, Oder W, Spatt J, Podreka I. Cerebral correlates of disturbed executive function and memory in survivors of severe closed head injury

54 Van Zomeren $\mathrm{AH}$, van den Burg W. Residual complaints of patients two years after severe head injury. $₹$ Neurol Neurosurg Psychiatry 1985;48:21-8.

55 Romano MD. Family response to traumatic head injury. Scand f Rehab Med 1974;6:1-4.

56 Rimel RW, Jane JA, Bond MR. Characteristics of the head injured patient. In: Rosenthal M, Griffith ER, Bond MR Miller JD, eds. Rehabilitation of the adult and child with traumatic brain injury. 2nd ed. Philadelphia: FA Davis, 1990:8-16. 